\title{
Efeitos da Leitura de Histórias no Desenvolvimento da Linguagem de Crianças de Nível Sócio-econômico Baixo
}

\author{
Maria José de Oliveira Fontes ${ }^{2}$ \\ Universidade Federal de Vicosa \\ Cláudia Cardoso-Martins \\ Universidade Federal de Minas Gerais
}

\begin{abstract}
Resumo
O presente estudo investiga o impacto de um programa de leitura de histórias no desenvolvimento de habilidades da linguagem oral e escrita de crianças de baixo nível sócio-econômico. Trinta e oito crianças entre 4 e 6 anos de idade participaram do estudo. As crianças designadas para o grupo experimental foram submetidas a um programa interativo de leitura de histórias. As crianças designadas para o grupo controle não foram submetidas a nenhum tratamento especial. Os resultados sugerem que programas interativos de leitura de histórias podem ter um impacto positivo no desenvolvimento da linguagem oral de crianças de classe sócio-econômica baixa. Embora os dois grupos tenham apresentado níveis comparáveis de desenvolvimento da linguagem no início do estudo, as crianças do grupo experimental excederam as crianças do grupo controle em todas as medidas de compreensão de história e vocabulário administradas após o término do programa de treinamento.

Palavras-chave: Leitura de histórias; linguagem escrita; linguagem oral.
\end{abstract}

Effects of Story Reading on Low SES Children's Language Development

\begin{abstract}
The present study investigates the impact of an interactive book reading program on the development of low SES children's oral and written language skills. Participants were 38 4- to 6-year-old Brazilian children. The children assigned to the experimental group underwent a training program of story reading that encouraged the children to play an active role in meaning construction through conversations about the story's characters and events. The children from the control group were not subjected to any special treatment. The results suggest that interactive book reading programs may have a positive impact on low SES children's oral language skills. Although the two groups showed similar levels of language development in the beginning of the study, the children in the experimental group performed better than the children in the control group on the measures of story comprehension and vocabulary which were administered after the training program.

Keywords: Book reading; oral language; written language.
\end{abstract}

O presente estudo investiga o impacto de um programa de leitura de histórias sobre o desenvolvimento da linguagem de crianças em idade pré-escolar. Em particular, o estudo investiga em que medida um programa interativo de leitura de histórias pode promover o desenvolvimento do vocabulário e da compreensão de histórias de crianças provenientes de famílias de baixa renda. A questão é obviamente relevante, tendo em vista a importância dessas habilidades para o sucesso escolar.

Os resultados de vários estudos (Ex.: Edwards, 1990; Feitelson, Goldstein, Iraqui \& Share, 1993; Mason, Kerr, Sinha \& McCormick, 1990; Robbins \& Ehri, 1994;

\footnotetext{
${ }^{1}$ Agradecimentos: Este artigo baseia-se nos resultados da dissertação de mestrado submetida pela primeira autora ao programa de Mestrado em Psicologia da Universidade Federal de Minas Gerais. Agradecemos à Coordenação de Aperfeiçoamento de Pessoal de Nível Superior (CAPES) e ao Conselho Nacional de Desenvolvimento Científico e Tecnológico $(\mathrm{CNPq})$, pelo seu apoio. Somos gratas também às crianças que participaram do estudo, às suas famílias e às monitoras das creches do município de Viçosa, MG, pela atenção e disponibilidade.

${ }^{2}$ Endereço para correspondência: Cláudia Cardoso Martins, Av. Antonio Carlos, 6627, Departamento de Psicologia, Universidade Federal de Minas Gerais, Pampulha, 31270 901, Belo Horizonte, MG. E-mail: cacau@fafich.ufmg.br
}

Rosenhouse, Feitelson, Kita \& Goldstein, 1997; Whitehurst \& cols., 1988) sugerem que a experiência de ouvir histórias desempenha um papel importante no desenvolvimento da linguagem. Por exemplo, no estudo de Wells (1986), a freqüência com que as crianças escutavam histórias aos 5 anos de idade correlacionou-se significativamente com a extensão do seu vocabulário até a idade de 10 anos. A leitura de histórias é, com efeito, uma ocasião potencialmente rica para o desenvolvimento do vocabulário, em virtude do fato de as histórias conterem pistas contextuais que ajudam a decifrar o sentido de palavras desconhecidas (Ex.: Nagy \& Herman, 1988). Somadas às ilustrações dos livros e às pistas não-lingüísticas e para-lingüísticas usadas pelo leitor - por exemplo, gestos e expressões faciais, entonação e ritmo - as pistas contextuais constituem uma fonte poderosa de informações sobre o significado de palavras desconhecidas. Embora essas pistas pareçam ser eficientes em si mesmas, há evidência (Whitehurst \& cols., 1988) de que a participação ativa da criança na construção do significado é um aspecto importante dos programas de leitura de histórias. 
Um exemplo de programa interativo de leitura de histórias é o programa de leitura dialógica desenvolvido por Whitehurst e colaboradores (1988) na Universidade de New York em Stony Brook. A leitura dialógica caracteriza-se pela utilização, por parte do leitor, de técnicas evocativas, cujo objetivo é estimular a participação da criança, assim como de feedback freqüente à produção verbal da criança, na forma de expansões, correções e elogios. Desde a sua formulação, o programa tem sido implementado com sucesso, tanto por mães como por professores, entre crianças de classe média/ média-alta e crianças de baixo nível sócio-econômico. Por exemplo, Valdez-Menchaca e Whitehurst (1992) relataram resultados positivos para um grupo de crianças mexicanas de 2 anos de idade, provenientes de famílias de baixo nível sócio-econômico. No estudo desses pesquisadores, as crianças submetidas ao programa de leitura dialógica apresentaram um desempenho significativamente superior ao desempenho de um grupo de crianças submetidas a um programa envolvendo atividades não verbais como, por exemplo, desenhar, colorir, montar quebra-cabeças, etc., em vários testes padronizados de linguagem. Elas também produziram um número significativamente maior de expressões verbais, sentenças mais longas e mais complexas, e maior variedade de nomes e de verbos ao folhearem um livro de história com o professor, do que as crianças cujo treinamento não incorporou a leitura de histórias.

A experiência de ouvir histórias também parece contribuir para o desenvolvimento da linguagem de crianças mais velhas. Por exemplo, Feitelson e colaboradores (1993) investigaram o impacto de um programa de leitura de histórias envolvendo crianças israelenses entre 5 e 6 anos de idade, isto é, em torno da idade em que as crianças começam a aprender a ler em Israel. As crianças designadas para o grupo experimental foram submetidas a um programa de leitura de histórias, enquanto as crianças do grupo controle continuaram participando do programa habitual da escola, o qual não incluía aquele tipo de experiência. Embora os dois grupos de crianças tenham apresentado um desempenho semelhante em um teste de vocabulário por ocasião do início do estudo, após o treinamento, as crianças do grupo experimental apresentaram um desempenho superior ao desempenho das crianças do grupo controle em uma série de medidas: elas erravam menos na leitura em voz alta, compreendiam melhor textos lidos silenciosamente e utilizavam uma linguagem mais sofisticada para contar histórias. Resultados semelhantes foram encontrados por Feitelson, Kita e Goldstein (1986) e Karweit (1994), entre outros.

Que aspectos da leitura interativa de histórias são particularmente benéficos para o desenvolvimento da linguagem? Dickinson e Smith (1994) abordaram essa questão em um estudo envolvendo crianças norte-americanas provenientes de famílias de baixo nível sócio econômico e seus professores. O objetivo principal daqueles pesquisadores era identificar os padrões de interação entre professores e crianças durante a leitura de histórias. Além disso, Dickinson e Smith estavam interessados em examinar a relação entre os diferentes padrões de interação e o desenvolvimento da linguagem oral.

A observação do padrão de interação ocorreu quando as crianças tinham, em média, 4 anos de idade. Nessa ocasião, Dickinson e Smith gravaram uma sessão de leitura de histórias em cada uma das 25 classes envolvidas. Um ano mais tarde, as crianças foram submetidas a um teste de vocabulário receptivo e a um teste de compreensão de história.

Com base nas gravações das sessões de leitura de história, Dickinson e Smith (1994) identificaram três tipos de abordagens: a abordagem co-construtiva, a abordagem didático-interacional e a abordagem orientada para $\mathrm{O}$ desempenho. A primeira caracterizava-se por uma quantidade elevada de interações entre o professor e as crianças durante a leitura da história. O professor geralmente complementava as passagens da história, tanto espontaneamente como em resposta aos comentários e às perguntas das crianças.

$\mathrm{Na}$ abordagem didático-interacional, as interações ocorriam menos freqüentemente, tanto durante, como antes e após a leitura da história. De uma maneira geral, o professor assumia o papel de liderança - era ele, por exemplo, quem fazia as perguntas, as quais giravam em torno dos eventos ocorridos na história.

Ao contrário das abordagens co-construtiva e didáticointeracional, a abordagem orientada para o desempenho caracterizava-se por uma incidência relativamente alta de interações antes e depois da leitura da história. Em particular, a introdução da história e do seu tema era prolongada. Durante a leitura, o professor encorajava as crianças a fazer previsões acerca do que iria acontecer na história, a estabelecer conexões entre os eventos da história e as suas experiências pessoais, além de acrescentar informações relevantes para a compreensão da mesma. A discussão, que ocorria após a leitura, era conduzida de duas maneiras: o professor reconstruía a história com a participação das crianças ou, então, procurava fazer um elo entre a história e as experiências de vida das crianças.

Segundo Dickinson e Smith (1994), as crianças cujos professores utilizaram a abordagem orientada para o desempenho apresentaram um desempenho superior ao das crianças submetidas à abordagem didático-interacional no teste de vocabulário administrado um ano após a observação da interação. Dickinson e Smith sugeriram que a superioridade da abordagem orientada para o desempenho decorreu provavelmente da alta incidência do que eles chamaram de conversas analíticas, isto é, interações verbais 
envolvendo a análise dos personagens e eventos, previsões dos eventos futuros e discussões sobre o vocabulário. Com efeito, a freqüência dessa variável correlacionou-se significativamente com o vocabulário e a habilidade de compreensão das crianças aos 5 anos de idade, mesmo após o controle do efeito de variações na quantidade total de interação verbal entre professores e crianças.

O presente estudo investiga o efeito de um programa de leitura de histórias que incorpora as características da abordagem orientada para o desempenho sobre o desenvolvimento da linguagem de crianças brasileiras provenientes de famílias de baixa renda. Em particular, o estudo examina o impacto da experiência de ouvir histórias sobre o desenvolvimento do vocabulário, da compreensão de histórias, e de diversas habilidades de leitura e escrita. Com base na literatura existente, esperava-se encontrar um efeito positivo para as habilidades de linguagem oral investigadas, isto é, o vocabulário e a compreensão de histórias. Por outro lado, não era esperado que a intervenção pudesse ter um efeito positivo (ou negativo) sobre o desenvolvimento das habilidades de leitura e escrita. Embora alguns pesquisadores tenham sugerido que a experiência de ouvir histórias apresenta um efeito positivo sobre o desenvolvimento da leitura e da escrita (Ex.: Cagliari, 1995; Rego, 1988; Wells, 1986; Whitehurst \& cols., 1994a, 1994b), há evidência de que esse efeito limita-se a crianças que conhecem os nomes e os sons das letras (Ehri \& Sweet, 1991). Como é descrito a seguir, esse não era o caso das crianças que participaram do presente estudo.

\section{Método}

\section{Participantes}

Participaram do estudo 38 crianças (18 meninas, 20 meninos) entre 5 e 6 anos de idade ( $m=62,5$ meses; $d p=4,15$ meses). No Teste das Matrizes Progressivas de Raven Escala Especial (Angelini \& cols., 1999), as crianças apresentaram percentis que variavam entre 1 e $80(m=27,83$; $d p=23,34$ ). Todas eram provenientes de famílias de baixo nível sócio-econômico, com renda familiar inferior a dois salários mínimos ( $m=\mathrm{R} \$ 162,21 ; \not p=29,07)$. O salário mínimo na ocasião do estudo era $\mathrm{R} \$ 112,00$. De uma maneira geral, as crianças moravam com a mãe e o pai ou padrasto. A imensa maioria das mães trabalhava fora como domésticas em casas de família.

As crianças foram selecionadas entre 100 crianças matriculadas em 12 creches públicas do município de Viçosa, Minas Gerais. Com o objetivo de formar um grupo experimental e um grupo controle, as crianças foram emparelhadas em relação às seguintes variáveis: sexo, idade cronológica, renda familiar, creche freqüentada, tempo de freqüência à creche e, finalmente, desempenho no teste de Raven. Um total de 21 pares de crianças foram formados, em sete das 12 creches. Para cada par, uma criança foi designada, por meio de sorteio, para o grupo experimental e a outra para o grupo controle. Dois pares foram eliminados do estudo, tendo em vista que, em cada um deles, uma criança deixou de freqüentar a creche antes do início da intervenção.

\section{Pré-testes}

Antes do início do programa de intervenção, as crianças selecionadas para participar do estudo foram submetidas a vários testes. Os testes foram administrados individualmente, na creche freqüentada pela criança. Com exceção dos testes de conhecimento dos nomes e sons das letras (ver abaixo), que foram administrados no mesmo dia, todos os testes foram administrados em dias separados, na ordem descrita a seguir.

1. Conhecimento dos nomes das letras. O examinador apresentava um cartão com as letras do alfabeto dispostas em ordem aleatória e pedia para a criança nomear cada uma delas. Apenas letras maiúsculas foram utilizadas, tendo em vista a evidência de que as crianças em idade pré-escolar tem mais familiaridade com as letras maiúsculas do que com as letras minúsculas (Silva, 1988).

2. Conhecimento dos sons das letras. A tarefa da criança consistia em identificar letras correspondendo a sons enunciados pelo examinador. O teste consistia de 1 item de treinamento e 15 itens experimentais. Dezesseis cartões, cada um contendo 6 letras maiúsculas impressas em uma fileira horizontal no centro do cartão, foram confeccionados para a tarefa. Para cada item, o examinador apresentava o cartão correspondente, e pedia para a criança identificar a letra que "fazia" o som enunciado pelo examinador.

3. Conhecimento da escrita. O teste era composto de 22 palavras, todas as quais começavam com uma consoante seguida de uma vogal. Em 11 palavras, o nome da consoante podia ser claramente detectado no início da pronúncia da palavra (Ex.: a palavra dedo, em que o nome da letra "d" coincide com a pronúncia da primeira sílaba da palavra); nas demais palavras, a consoante inicial representava o fonema tipicamente representado pela letra em Português (Ex.: a primeira letra na palavra dado corresponde ao fonema /d/). A criança era instruída a escrever apenas a primeira letra das palavras. Esse recurso foi adotado com o objetivo de não cansar a criança.

Cada resposta da criança recebia um escore que variava entre 0 e 2 pontos. Um escore igual a 2 era dado quando a criança escrevia corretamente a primeira consoante na palavra. A criança recebia um escore igual a 1 , quando escrevia corretamente a primeira vogal na palavra e um escore igual 
a zero, quando a letra escrita não correspondia nem à primeira consoante nem à primeira vogal na palavra. É importante observar que a classificação de uma resposta particular levava em consideração as outras respostas da criança. Ou seja, se a criança escrevia "d" para a palavra dedo, mas também escrevia "d" para outras palavras que não começavam com a letra "d", a resposta "d" para a palavra dedo não era considerada correta. O mesmo critério foi utilizado quando a letra era uma vogal. Por exemplo, se a criança escrevia a letra "a" para a palavra vacina e para outras palavras em que a primeira vogal não correspondia à letra "a", a resposta "a" para a palavra vacina não era levada em consideração.

4. Leitura de palauras. $\mathrm{O}$ teste avaliou a habilidade da criança de reconhecer algumas palavras freqüentemente encontradas em livros para crianças (Pinheiro \& Keys, 1987). Quinze palavras foram selecionadas para o estudo. As palavras apareciam impressas em letras maiúsculas no centro de cartões individuais. Para cada cartão, a criança era instruída a ler a palavra escrita. Cinco cartões contendo rótulos conhecidos (por exemplo, Coca-Cola) foram entremeados aos cartões contendo as palavras. Os rótulos foram incluídos com o objetivo de minimizar um possível sentimento de fracasso por parte das crianças uma vez que, segundo as monitoras das creches, nenhuma havia começado a ler por ocasião do estudo.

5. Vocabulário. O subteste de Vocabulário do Teste de Inteligência para Pré-escolares de David Wechsler (Wechsler, 2002) foi utilizado para avaliar o vocabulário das crianças. A tarefa da criança consistia em definir o significado de palavras enunciadas pelo examinador. A administração e correção do teste foram feitas de acordo com as normas descritas no manual.

6. Compreensão de história I. O teste avaliou a compreensão da criança de uma história - "O sonho de Maria" (Dias, Morais \& Oliveira, 1995) - lida em voz alta para ela. Após a leitura da história, o examinador pedia para a criança recontála em voz alta. Em seguida, eram feitas sete perguntas sobre a história. As respostas para algumas perguntas estavam expressas diretamente no texto, enquanto que para outras, as respostas podiam ser inferidas a partir do que havia sido lido. A história e as perguntas estão descritas no Apêndice A. Para cada uma das questões, a resposta da criança recebia um escore que variava entre 0 e 2 pontos, em função da sua elaboração. O Apêndice B apresenta exemplos de respostas classificadas de acordo desses escores.

\section{Programa de Treinamento}

Em cada uma das creches, as crianças designadas para o grupo experimental foram submetidas a um programa de treinamento que consistiu na leitura e discussão de 16 livros de literatura infantil, selecionados com a ajuda de coordenadoras de escolas particulares e creches dos municípios de Belo Horizonte e Viçosa e de uma bibliotecária da Biblioteca Pública Infantil e Juvenil de Belo Horizonte.

O programa teve a duração de quatro meses, com uma sessão por semana em cada uma das sete creches. Um livro de história diferente foi utilizado em cada uma das sessões. Ao todo, 112 sessões foram conduzidas, 16 para cada uma das 7 creches. Todas as sessões foram conduzidas pela primeira autora deste trabalho. A freqüência ao programa de treinamento foi bastante razoável, com as crianças atendendo, em média, a 13,8 das 16 sessões ( $(p=1,98)$. As crianças do grupo controle não foram submetidas a nenhum tipo de treinamento, mas continuaram participando das atividades levadas a cabo pela creche.

De uma maneira geral, as sessões de treinamento ocorreram sempre no mesmo dia da semana para cada uma das 7 creches envolvidas. Os horários foram definidos em função do horário das atividades de cada creche e da disponibilidade de espaço físico para a realização das sessões. Em cada creche, o treinamento era coletivo, ou seja, as crianças do grupo experimental (entre 2 e 4 crianças, no máximo) participavam juntas do treinamento. Cada sessão durava aproximadamente 30 minutos.

Durante as sessões, o examinador sentava-se diante das crianças, em um banco baixo. As crianças ficavam assentadas em um tapete ou colchonete da própria creche, de frente para o examinador. Essa disposição foi adotada com o objetivo de favorecer a interação entre o examinador e as crianças, permitindo também que as crianças vissem as ilustrações e o texto. Para isso, o examinador segurava o livro bem próximo às crianças. Todas as sessões foram gravadas e filmadas.

Conforme mencionamos anteriormente, foram adotadas as características da abordagem que Dickinson e Smith (1994) chamaram de orientada para o desempenho. $O$ procedimento utilizado antes, durante e após a leitura da história é descrito brevemente a seguir.

\section{Antes da leitura}

Antes de iniciar a leitura, o examinador mostrava a capa do livro e procurava envolver as crianças em conversas sobre o tema da história. Por exemplo, o examinador perguntava "Que título vocês acham que esta história tem?"; "Por que?"; "O que vocês acham que vai acontecer?", etc. Outras perguntas procuravam relacionar o tema da história com a experiência de vida da criança. Por exemplo, antes da leitura do livro "O Vestido de Kaká" (Dias, 1994), que relata a história de uma menina que só queria usar um vestido de palhacinho, o examinador perguntava: "Vocês tem um vestido ou uma roupa especial?"; "Como ela é?"; "Onde é que vocês guardam essa roupa?"; "Quando é que vocês usam essa roupa?", etc. 


\section{Durante a leitura}

A leitura era feita de forma pausada, com um tom de voz adequado. De acordo com a história, o examinador utilizava recursos não verbais e para-lingüísticos como, por exemplo, expressões faciais, gestos, mudança do tom da voz, etc.

Sempre que necessário, a leitura era interrompida, seja para responder aos comentários e às perguntas das crianças, seja para acrescentar informações relevantes. Além disso, as crianças eram freqüentemente solicitadas a analisar os sentimentos, ações e intenções dos personagens da história e, muitas vezes, o examinador aproveitava essas ocasiões para discutir o vocabulário do texto. A interação transcrita a seguir, a respeito de uma passagem do livro "O macaco vermelho" (Vale, 1992) ilustra ambos esses aspectos.

1- Examinador: Como o macaco estava se sentindo?

2- Criança 1: Triste.

3- Examinador: Isso mesmo. Ele estava triste. Por que ele estava triste?

4- Criança 2: Por que ele estava preso.

5- Examinador: Onde ele estava preso?

6- Criança 1: Na cadeia.

7- Examinador: Como chama isso? (mostrando a figura de uma jaula)

8- Criança 3: Negócio de leão.

9- Examinador: Isso aqui chama jaula; é onde ficam presos no circo, a onça, o tigre, e o leão. É como se fosse uma gaiola grande.

10- Criança 2: Cabe até elefante grande?

11- Examinador: Sim, se a jaula for grande, cabe até elefante grande.

As perguntas das crianças eram sempre consideradas com muita atenção. No entanto, ao invés de responder diretamente as questões das crianças, o examinador procurava estimulá-las a refletir sobre as mesmas e, sempre que possível, a fornecer elas próprias as respostas. Por exemplo, na história "O macaco medroso" (Junqueira, 1995), após o examinador ter lido a passagem que diz que o macaco Peteleco comia na hora de comer, na hora de brincar e na hora de dormir, uma criança perguntou:

1- Criança 1: Nossa, como que ele vai ficar?

2- Examinador: Como você acha que ele vai ficar? Olha aqui. (mostrando a figura do macaco)

3- Criança 1: Não sei não.

4- Examinador: E você (perguntando para a criança 2), como você acha que o Peteleco vai ficar?

5- Criança 2:Ah, eu acho que ele vai ficar bem gordão.

6- Examinador: Isso mesmo, ele vai ficar bem gordo, porque ele só quer saber de comer muita banana.

7- Criança 1: Eu como banana demais também. Eu vou ficar gordão.
8- Criança 3: Nós, na hora de dormir nós "dorme", na hora de brincar, nós "brinca", na hora de jantar, nós "janta”.

9- Examinador: Muito bem!

Finalmente, em momentos importantes da história, o examinador incitava as crianças a fazer pequenos resumos, de forma a assegurar a sua compreensão até aquele ponto. Por exemplo, na história “O Vestido de Kaká", Kaká insiste em vestir somente o vestido de palhacinho, mesmo após a mãe e a babá haverem mostrado outros vestidos para ela. O examinador então perguntava: "Por que será que o vestido de palhacinho ficou tão sujo?"

\section{Após a Leitura}

Após a leitura, o examinador fazia perguntas que variavam em número e conteúdo de acordo com a história. As perguntas seguiam sempre a mesma ordem e, de modo geral, envolviam a identificação e a integração dos principais eventos da história ou ainda a integração entre esses eventos e as experiências pessoais das crianças. Em alguns casos, quando as crianças solicitavam, era permitido a elas recontar a história.

\section{Pós-testes}

Encerrado o programa de treinamento, as crianças de ambos os grupos foram novamente submetidas aos testes que haviam sido administrados por ocasião do início do estudo. Dois novos testes foram também administrados: o teste de vocabulário receptivo de Peabody (Dunn \& Dunn, 1997) e um teste de compreensão de história. O teste de vocabulário receptivo consiste de uma série de cartões, cada qual contendo 4 gravuras diferentes. Para cada cartão, a criança é solicitada a identificar a gravura que melhor representa o significado da palavra enunciada pelo examinador. O teste foi administrado conforme as instruções especificadas no manual, com as palavras traduzidas para o português.

O novo teste de compreensão consistiu da leitura de uma história, intitulada "A flor e o passarinho" (Brandão, 1994). Conforme pode ser visto no Apêndice $C$, o enredo da história possui um número maior de enunciados do que a história "O sonho de Maria". Embora 11 perguntas tenham sido feitas após a leitura da história, optamos por considerar apenas as oito primeiras, uma vez que as perguntas de número 9 a 11 envolviam respostas bastante subjetivas e, conseqüentemente, de difícil correção.

Ambos os testes de compreensão foram corrigidos pela primeira autora. Um segundo juiz independente, que não sabia a que grupo as crianças pertenciam, avaliou $50 \%$ do teste administrado no início do ano e $50 \%$ de 
cada um dos dois testes administrados no final do estudo. A confiabilidade, avaliada como o número de acordos dividido pelo número de acordos e desacordos foi, respectivamente, 0,98 e 0,97 , para a primeira e segunda administração da história "O sonho de Maria" e 0,98, para o teste envolvendo a história "A flor e o passarinho".

\section{Entrevista com os pais das crianças}

No final do estudo, foi feita uma visita aos lares das crianças com o objetivo de coletar dados relativos à sua experiência com a linguagem escrita fora da creche. Com essa finalidade, elaboramos um questionário, o qual foi administrado aos pais da criança durante a visita. $\mathrm{O}$ questionário visou obter respostas para quatro itens básicos: escolaridade dos pais, acesso da criança a material escrito, freqüência com que os pais liam histórias para a criança e ensino da escrita pelos pais. Foi considerada apenas a escolaridade da mãe, porque havia casos em que os pais não moravam com as crianças e outros em que a escolaridade dos pais era desconhecida.

Cada um desses itens foi avaliado em função de duas ou mais categorias. Para o item "escolaridade dos pais", os pais que possuíam o $2^{\circ}$ grau incompleto ou completo foram classificados na categoria 1 , enquanto aqueles que possuíam o $1^{\circ}$ grau incompleto ou completo, incluindo o primário completo ou incompleto, foram classificados na categoria 2. Finalmente, os pais que nunca freqüentaram a escola foram classificados na categoria 3 .
Três categorias foram também derivadas para o item "acesso da criança a material escrito em casa". A categoria 1 abrigou as crianças que tinham acesso a dois ou mais tipos de material escrito em casa (Ex.: livros de história, jornais e revistas); as crianças que tinham acesso a apenas um tipo de material escrito (Ex.: revistas diversas) foram classificadas na categoria 2; e aquelas que não tinham acesso a nenhum tipo de material escrito em casa foram classificadas na categoria 3.

Para o item "freqüência de leitura pelos pais", a categoria 1 correspondia aos pais que diziam ler histórias duas ou mais vezes por semana para as crianças; a categoria 2 aos pais que diziam ler histórias menos de duas vezes por semana para as crianças; e a categoria 3, aos pais que nunca liam histórias para as crianças.

Finalmente, os pais foram divididos em dois grupos em função de suas respostas às perguntas 9 e 10: o grupo de pais que disseram ensinar a criança e o grupo daqueles que disseram nunca haver ensinado a criança a escrever.

\section{Resultados}

A Tabela 1 apresenta o número médio de respostas corretas para os pré- e pós-testes, separadamente para os dois grupos de crianças. Como pode ser visto nessa Tabela, os dois grupos de crianças não diferiram em relação ao seu desempenho nos pré-testes. Por outro lado, após o programa de intervenção, as crianças do grupo experimental

Tabela 1

Número Médio de Respostas Corretas (e Desvios-padrão) para as Medidas dos Pré e Pós-testes

\begin{tabular}{|c|c|c|c|c|}
\hline \multirow[t]{3}{*}{ Testes } & \multicolumn{4}{|c|}{ Grupo } \\
\hline & \multicolumn{2}{|c|}{ Experimental } & \multicolumn{2}{|c|}{ Controle } \\
\hline & Pré-teste & Pós-teste & Pré-teste & Pós-teste \\
\hline Letras-nome & 0,63 & 3,05 & 1,21 & 2,10 \\
\hline$(\max =24)$ & $(1,06)$ & $(4,36)$ & $(1,62)$ & $(3,16)$ \\
\hline Letras - som & 2,74 & 5,74 & 3,10 & 4,05 \\
\hline$(\max =24)$ & $(1,82)$ & $(3,0)$ & $(1,33)$ & $(2,07)$ \\
\hline Escrita & 0,05 & 2,32 & 0,79 & 2,89 \\
\hline$(\max =44)$ & $(0,23)$ & $(5,59)$ & $(2,35)$ & $(5,79)$ \\
\hline Vocabulário WPPSI & 9,32 & 14,95 & 9,16 & 12,68 \\
\hline$(\max =44)$ & $(3,07)$ & $(3,31)$ & $(5,49)$ & $(4,19)$ \\
\hline Vocabulário PPVT III-A a & & 65,58 & - & 49,84 \\
\hline$(\max =244)$ & - & $(14,08)$ & & $(19,57)$ \\
\hline Compreensão I & 2,85 & 9,79 & 3,53 & 6,00 \\
\hline$(\max =14)$ & $(2,50)$ & $(1,87)$ & $(4,09)$ & $(4,36)$ \\
\hline Compreensão II ${ }^{\text {b }}$ & & 13,32 & & 9,89 \\
\hline$(\max =16)$ & - & $(2,96)$ & - & $(5,76)$ \\
\hline
\end{tabular}

Nota. ${ }^{2}$ Escores brutos; ${ }^{\mathrm{b}}$ Testes administrados apenas após a intervenção 
apresentaram um desempenho superior ao das crianças do grupo controle em vários dos pós-testes.

Em vista do número pequeno de participantes, o teste de sinal (Siegel, 1956) para amostras dependentes foi utilizado para avaliar a significância das diferenças encontradas entre os dois grupos de crianças após o programa de treinamento. Para as medidas administradas no início e no final do estudo, comparamos os dois grupos em relação ao número de pontos ganhos entre o pré e o pós-teste. Nos casos em que o escore no pós-teste foi inferior ao escore no pré-teste, o ganho foi considerado nulo.

Conforme esperado, o ganho do grupo experimental foi significativamente superior ao ganho do grupo controle para a medida de compreensão da história "O sonho de Maria" $(p=0,004)$, e para a medida de vocabulário expressivo $(p=0,015)$. Por outro lado, os dois grupos não diferiram significativamente em relação ao ganho nas medidas de conhecimento dos nomes e dos sons das letras e, nem tampouco, em relação ao ganho na medida de conhecimento da escrita (todos os $p s>0,10)$.

Conforme mencionamos anteriormente, o teste de compreensão da história "A flor e o passarinho" e o teste de vocabulário receptivo foram administrados apenas no final do estudo. Conforme esperávamos, as crianças do grupo experimental apresentaram um resultado significativamente superior ao das crianças do grupo controle, em ambos os testes $(\operatorname{ambos}$ os $p s<0,05)$.

\section{O subgrupo como a unidade de análise}

Para as análises descritas anteriormente, a unidade de análise foi a criança individual. Uma vez que a intervenção

Tabela 2

Número Médio de Respostas Corretas nos Pré-testes para os Sete Subgrupos

\begin{tabular}{|c|c|c|c|c|c|c|c|c|c|c|}
\hline \multirow[t]{3}{*}{ Subgrupos } & \multicolumn{10}{|c|}{ Grupo } \\
\hline & \multicolumn{5}{|c|}{ Experimental } & \multicolumn{5}{|c|}{ Controle } \\
\hline & $\begin{array}{c}\text { Letras } \\
\text { nome } \\
(\max =24)\end{array}$ & $\begin{array}{c}\text { Letras } \\
\text { som } \\
(\max =24)\end{array}$ & $\begin{array}{r}\text { Escrita } \\
(\max =44)\end{array}$ & $\begin{array}{c}\text { Vocab. } \\
\text { WPSSI } \\
(\max =44)\end{array}$ & $\begin{array}{l}\text { Comp.I }{ }^{a} \\
(\max =14)\end{array}$ & $\begin{array}{l}\text { Letras } \\
\text { nome } \\
(\max =24)\end{array}$ & $\begin{array}{l}\text { Letras } \\
\text { som } \\
(\max =24)\end{array}$ & $\begin{array}{l}\text { Escrita } \\
(\max =44)\end{array}$ & $\begin{array}{l}\text { Vocab. } \\
\text { WPSSI } \\
(\max =14)\end{array}$ & $\begin{array}{l}\text { Comp.I }{ }^{a} \\
(\max =14)\end{array}$ \\
\hline 1 & 0,66 & 2,66 & 0 & 9,66 & 2,33 & 0,66 & 2,33 & 0 & 5,0 & 1,66 \\
\hline 2 & 1,5 & 1,0 & 0 & 6,0 & 2,0 & 2,0 & 4,0 & 0,5 & 5,5 & 1,0 \\
\hline 3 & 0,33 & 2,0 & 0 & 10,33 & 2,0 & 1,33 & 3,33 & 0,33 & 13,0 & 5,66 \\
\hline 4 & 0,25 & 3,25 & 0 & 10,75 & 17,5 & 0,25 & 3,75 & 0,5 & 7,25 & 1,0 \\
\hline 5 & 1,0 & 3,33 & 1,0 & 7,66 & 4,0 & 2,33 & 3,0 & 0 & 10,66 & 5,66 \\
\hline 6 & 1,0 & 4,5 & 0 & 9,0 & 4,0 & 1,5 & 1,5 & 0 & 13,0 & 6,0 \\
\hline 7 & 0 & 2,0 & 0 & 10,5 & 5,0 & 1,0 & 3,5 & 1,5 & 6,0 & 5,0 \\
\hline
\end{tabular}

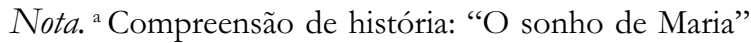

Tabela 3

Número Médio de Respostas Corretas nos Pós-testes para os Sete Subgrupos

\begin{tabular}{|c|c|c|c|c|c|c|c|c|c|c|c|c|c|c|}
\hline \multirow{2}{*}{\multicolumn{2}{|c|}{ Subgrupos }} & \multicolumn{13}{|c|}{ Grupo } \\
\hline & & \multicolumn{6}{|c|}{ Experimental } & \multicolumn{7}{|c|}{ Controle } \\
\hline & \multirow{4}{*}{$\begin{array}{c}\text { Letras } \\
\text { nome } \\
(\max =24\end{array}$} & \multirow{3}{*}{$\begin{array}{l}\text { Letras } \\
\text { som }\end{array}$} & \multirow{4}{*}{$\begin{array}{l}\text { Escrita } \\
(\max =44)\end{array}$} & \multirow{3}{*}{$\begin{array}{c}\text { Vocab. } \\
\text { WPSSI } \\
(\max =44)\end{array}$} & \multirow{3}{*}{ Comp. I } & \multirow{4}{*}{$\begin{array}{l}\text { Comp.II } \\
(\max =16)\end{array}$} & \multirow{4}{*}{$\begin{array}{l}{ }^{c} \text { Vocab. } \\
\text { PPV } \\
\text { TIIIA }{ }^{c} \\
\text { (max=24 }\end{array}$} & \multirow{4}{*}{$\begin{array}{r}\text { Letras } \\
\text { nome } \\
\text { (max=24 }\end{array}$} & \multirow{4}{*}{$\begin{array}{c}\text { Letras } \\
\text { som }\end{array}$} & \multirow{4}{*}{ Escrita } & \multirow{4}{*}{$\begin{array}{r}\text { Vocab. } \\
\text { WPSSI } \\
(\max =44)\end{array}$} & \multirow[t]{2}{*}{ Comp. $I^{a}$} & \multirow{2}{*}{ Comp.II } & \multirow{4}{*}{$\begin{array}{l}\text { bc Vocab. } \\
\text { PPVT } \\
\text { (9) } I I A^{c} \\
(\max =244\end{array}$} \\
\hline & & & & & & & & & & & & & & \\
\hline & & & & & & & & & & & & $(\mathrm{ma}$ & $(\max =10)$ & \\
\hline & & $(\max =24)$ & & & & & & & & & & & & \\
\hline 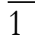 & 4,33 & 6,33 & 1,33 & 16,33 & 8,0 & 14,33 & 58,66 & 0,33 & 4,0 & 0,33 & 11,33 & 5,66 & 10,0 & 46,9 \\
\hline & 1,0 & 9,0 & 1,0 & 14,00 & 8,0 & 13,00 & 71,0 & 0,5 & 3,0 & 1,0 & 10,0 & 1,5 & 9,0 & 44,0 \\
\hline & 2,0 & 5,33 & 1,66 & 13,66 & 9,33 & 11,66 & 100,0 & 2,66 & 5,0 & 1,33 & 14,33 & 8,66 & 11,0 & 87,0 \\
\hline & 1,0 & 5,75 & 0,75 & 13,0 & 11,00 & 13,00 & 59,25 & 0,5 & 2,75 & 1,0 & 9,5 & 4,25 & 7,5 & 30,5 \\
\hline & 9,66 & 6,66 & 3,0 & 17,33 & 11,33 & 14,33 & 73,0 & 6,33 & 5,66 & 2,66 & 16,33 & 7,66 & 10,66 & 55,33 \\
\hline & 0 & 2,0 & 0 & 11,5 & 10,5 & 11,00 & 77,0 & 2,0 & 3,5 & 0,5 & 16,5 & 7,5 & 14,5 & 65,5 \\
\hline 7 & 2,0 & 4,5 & 0,5 & 19,5 & 9,5 & 16,0 & 78,0 & 2,5 & 4,5 & 1,0 & 12,0 & 6,5 & 8,0 & 64,0 \\
\hline
\end{tabular}

Nota. ${ }^{a}$ Compreensão de história: "O sonho de Maria"; ${ }^{b}$ Compreensão de história: "A flor e o passarinho"; Estes testes foram administrados somente na fase final do estudo. 
não foi realizada individualmente, mas em pequenos grupos, as análises foram refeitas considerando o subgrupo como a unidade de análise. As Tabelas $2 \mathrm{e} 3$ apresentam respectivamente as médias nos pré e pós-testes, separadamente para cada um dos sete subgrupos experimentais e de controle. Novamente, o teste de sinal foi utilizado para avaliar a significância das diferenças encontradas entre os subgrupos experimentais e os subgrupos de controle em relação ao ganho entre o pré e o pós-teste, para as medidas administradas tanto no início como no final do estudo, e em relação aos escores no teste de compreensão da história "A flor e o passarinho" e do teste de vocabulário receptivo, administrados apenas após a intervenção.

Como os resultados das análises descritas anteriormente, não houve diferenças significativas entre os subgrupos experimentais e os subgrupos de controle em relação aos pré-testes (todos os $p s>0,10$ ).

$\mathrm{Na}$ análise dos ganhos obtidos por cada subgrupo entre o pré e o pós-teste, não foi encontrada uma diferença significativa entre os dois grupos em relação às medidas de leitura e escrita. Por outro lado, houve uma diferença significativa favorecendo os subgrupos experimentais para a medida de compreensão da história "O sonho de Maria" $(p=0,008)$.

Para a medida de vocabulário expressivo, a diferença entre os ganhos dos subgrupos experimentais e de controle não foi significativa. Contudo, a diferença favoreceu a maioria dos subgrupos experimentais. De fato, como pode ser visto na Tabela 3, cinco dos subgrupos experimentais apresentaram ganhos maiores do que os seus respectivos subgrupos de controle. Em apenas um par, a diferença favoreceu o subgrupo controle.

Nos testes administrados apenas após a intervenção, a diferença favoreceu significativamente os sujeitos experimentais no que diz respeito à medida de vocabulário receptivo $(p=0,008)$. Para a medida de compreensão da história "A flor e o passarinho", a diferença entre os dois grupos foi marginalmente significativa $(p=0,062)$.

\section{A experiência com a linguagem escrita no lar}

É pouco provável que as diferenças encontradas entre as crianças do grupo experimental e as crianças do grupo controle tenham resultado de uma diferença entre os dois grupos em relação à experiência com a linguagem escrita em casa. Conforme é descrito a seguir, as respostas dos pais ao questionário foram muito semelhantes para os dois grupos de crianças. Além disso, as poucas diferenças encontradas favoreceram as crianças do grupo controle, e não as crianças do grupo experimental.

A grande maioria das mães das crianças do grupo experimental $(94,7 \%)$ e das mães das crianças do grupo controle $(78,9 \%)$ possuía o $1^{\circ}$ grau incompleto ou completo, incluindo o primário completo ou incompleto. Com efeito, o número médio de anos na escola foi $4,6(d p=1,8)$, para as mães das crianças do grupo experimental e $4,5(d p=2,8)$, para as mães das crianças do grupo controle.

A julgar pelas respostas das mães, a maioria das crianças de ambos os grupos $(63,15 \%$ das crianças do grupo experimental e $57,9 \%$ das crianças do grupo controle) tinha acesso a poucos tipos de material escrito em casa. Em ambos os grupos, o material escrito mais freqüente consistia de revistas de diversos tipos, doadas por terceiros. Entretanto, houve uma diferença entre os dois grupos no que diz respeito à experiência com livros de história. Com base no relato dos pais, $42 \%$ das crianças do grupo controle possuíam livros de histórias, contra apenas $15,8 \%$ das crianças do grupo experimental.

Para o item "freqüência de leitura pelos pais", houve uma predominância da categoria 2 (isto é, leitura de 1 livro de história a cada 15 dias) tanto no grupo experimental (52,6\%) como no grupo controle (57,9\%). Por outro lado, um número relativamente maior de mães do grupo experimental relatou nunca haver lido um livro de história para as suas crianças (31,6\% em oposição a 10,5\% das mães do grupo controle).

Finalmente, em relação ao item "ensino da escrita pelos pais", a maioria das mães das crianças do grupo experimental $(78,9 \%)$ e das mães das crianças do grupo controle $(68,4 \%)$ afirmou ensinar ou já haver ensinado a criança a escrever alguma coisa, em geral, o nome da criança.

\section{Discussão}

Os resultados do presente estudo sugerem que a leitura interativa de histórias para crianças em idade pré-escolar desempenha um papel importante no desenvolvimento da linguagem. Contudo, os resultados do presente estudo sugerem que o impacto desse tipo de experiência limita-se às habilidades de linguagem oral.

De uma maneira geral, não foi observada nenhuma diferença entre os dois grupos de crianças em relação às medidas de conhecimento da leitura e da escrita que foram utilizadas no presente estudo, quer antes quer após o programa de treinamento. Os resultados questionam, portanto, a sugestão de que a leitura de livros de histórias na préescola facilita a aprendizagem posterior da leitura e da escrita (Ex.: Feitelson \& cols., 1986; Wells, 1986). É possível, no entanto, que algumas características do presente estudo tenham contribuído para esses resultados negativos. Por exemplo, as crianças que participaram do estudo tinham muito pouco conhecimento da língua escrita. A maioria conhecia os nomes de apenas uma ou duas letras do alfabeto. Não é surpreendente, portanto, que elas ainda não compreendessem 
que a escrita representa sons ou que não houvessem ainda começado a ler. Conforme mencionamos anteriormente, é possível que a leitura de livros de história tenha um impacto positivo sobre a aprendizagem da leitura e da escrita apenas entre crianças que já conhecem os nomes ou sons das letras (Ex.: Ehri \& Sweet, 1991).

Uma outra possibilidade é que a experiência de ouvir histórias tenha um maior impacto em fases mais avançadas da aquisição da leitura, quando a compreensão torna-se mais importante. Com efeito, as crianças do grupo experimental apresentaram ganhos consideráveis, tanto no que diz respeito ao desenvolvimento do vocabulário, como em relação ao desenvolvimento da compreensão de histórias, habilidades obviamente necessárias para a compreensão da leitura.

É possível que o efeito positivo encontrado para o programa de intervenção deva-se ao fato de o programa haver incorporado aspectos da abordagem que Dickinson e Smith (1994) identificaram como orientada para o desempenho. Em outras palavras, durante todas as sessões de leitura, as crianças tiveram amplas oportunidades de analisar, fazer previsões e discutir acerca dos principais eventos e personagens das histórias.

Os benefícios de uma leitura interativa para a compreensão de histórias têm sido apontados por vários autores (Ex.: Adams \& Bruce, 1982; Olson, 1977; Terzi, 1995). Muito provavelmente, as crianças do grupo experimental incorporaram a atitude analítica exemplificada pelo orador por meio dos seus comentários e questões durante a leitura das histórias. Isso explicaria porque, a despeito de um desempenho semelhante no início do estudo, aquelas crianças apresentaram um desempenho significativamente superior ao das crianças do grupo controle nos pós-testes.

A leitura de histórias em voz alta também constitui uma oportunidade favorável ao desenvolvimento do vocabulário. Com efeito, o contexto verbal das histórias, assim como a entonação e o ritmo do leitor constituem uma fonte rica para o desenvolvimento do vocabulário (Nagy \& Herman, 1987). Não é surpreendente, portanto, que o nosso programa de intervenção tenha tido um impacto positivo sobre o desenvolvimento do vocabulário.

O presente estudo apresenta várias limitações. Provavelmente, a limitação mais importante diz respeito à ausência de um programa de intervenção alternativo para as crianças do grupo controle. Uma vez que essas crianças não foram submetidas a nenhum tratamento especial, não é possível descartar a hipótese de que o efeito positivo encontrado para o nosso programa tenha resultado de fatores alheios à leitura de histórias. No entanto, o fato dos resultados serem consistentes com os resultados de outros estudos reforça a conclusão de que programas interativos de leitura de histórias são importantes para o desenvolvimento da linguagem oral.

Um desafio importante para a pesquisa futura consistirá em investigar o efeito de um programa interativo de leitura de histórias em que o leitor limita-se a ler a história para as crianças. A julgar pelos resultados do estudo de Whitehurst e colaboradores (1988), o envolvimento ativo da criança durante a leitura é importante para o desenvolvimento do vocabulário.

Whitehurst e colaboradores (1988) investigaram os efeitos da leitura dialógica na aquisição do vocabulário de 30 crianças norte-americanas de 2 anos de idade. As mães das crianças do grupo experimental foram instruídas a ler histórias para seus filhos de acordo com as diretrizes da leitura dialógica. Ou seja, elas foram treinadas a encorajar as suas crianças a participar ativamente da leitura da história, e a expandir e reforçar os esforços das crianças nesse sentido. As mães das crianças do grupo controle foram simplesmente instruídas a ler as mesmas histórias para os seus filhos. Ao cabo de um mês, ambos os grupos de crianças foram submetidos a testes que avaliavam o vocabulário expressivo e receptivo.

Segundo Whitehurst e colaboradores (1988), ao contrário das crianças do grupo experimental, as crianças cujas mães simplesmente leram as histórias, sem procurar envolvê-las ativamente durante a leitura, não apresentaram ganhos significativos no vocabulário ao final do programa de intervenção. Conforme observamos anteriormente, contudo, as crianças que participaram do estudo de Whitehurst tinham apenas 2 anos de idade. Será necessário investigar em que medida isso também é verdadeiro para crianças mais velhas.

Uma outra limitação do presente estudo diz respeito ao número pequeno de crianças que participaram das sessões de leitura. Os subgrupos experimentais tinham 2 ou 3 crianças. Apenas um subgrupo foi composto por 4 crianças. O número relativamente pequeno de crianças possibilitou que todas participassem ativamente de todas as etapas da leitura de histórias. Estudos futuros deverão avaliar o efeito da leitura de histórias em grupos compostos por um número maior de crianças, como o que ocorre em uma sala de aula comum.

É importante ressaltar ainda que o programa foi desenvolvido por um profissional de nível superior, com ampla experiência acadêmica e profissional em Educação Infantil. Estudos investigando os efeitos de programas interativos de leitura de histórias levados a cabo por profissionais menos experientes são, portanto, necessários.

Apesar dessas limitações, o fato de resultados positivos terem sido observados ao término de apenas 12 sessões de leitura de histórias parece bastante encorajador e sugere que a leitura interativa de histórias poderá ser valiosa para os programas de educação infantil, sobretudo para crianças 
provenientes de classes sócio-econômicas desfavorecidas. A pesquisa futura deverá investigar os possíveis efeitos a longo prazo dessa prática educacional. Como sugerimos anteriormente, é possível que essa experiência contribua para a compreensão da leitura e, como conseqüência, para o desempenho escolar da criança como um todo.

\section{Referências}

Adams, M. \& Bruce, B. (1982). Background knowledge and reading comprehension. Em M. L. Smith-Burke (Org.), Reader meets author: Bridging the gap (pp. 2-26). Newark, Delaware: International Reading Association.

Angelini, A. L. \& cols. (1999). Matrizes Progressivas Coloridas de Raven: Escala especial. São Paulo: Centro Editor de Testes e Pesquisas em Psicologia.

Brandão, A. C. P. (1994). A produção e compreensão de histórias em crianças. Dissertação de Mestrado não-publicada, Programa de Pós-graduação em Psicologia, Universidade Federal de Pernambuco. Recife, Pernambuco.

Cagliari, L. C. (1995). Alfabetização e lingüistica (8 ed.). São Paulo: Scipione.

Dias, M. G. B., Morais, E. P. M. \& Oliveira, M. C. N. P. (1995). Dificuldades na compreensão de textos: Uma tentativa de remediação. Arquivos Brasileiros de Psicologia, 47(4), 13-24.

Dias, V. L. (1994). O vestido de Kaká. Belo Horizonte: Dimensão.

Dickinson, D. K. \& Smith, M. W. (1994). Long-term effects of preschool teachers' book readings on low-income children's vocabulary and story comprehension. Reading Research Quarterly, 29, 105-122.

Dunn, L. M. \& Dunn, L. M. (1997). PPV T: III-A Peabody Picture Vocabulary Test ( $3^{\text {rd }}$ ed.). Circle Pines, Minnesota: American Guidance Service.

Edwards, P. A. (1990). Supporting lower SES mother's attempts to provide scaffolding for book reading. Em L. Allen \& J. Mason (Orgs.), Risk makers, risk takers, and risk, breaks: Reducing the risks for young literacy learners (pp. 222250). Portsmouth, NH: Heinemann.

Ehri, L. C. \& Sweet, J. (1991). Finger-point reading of memorized text: What enables to process the print? Reading Research Quarterly,26, 442-462.

Feitelson, D., Goldstein, Z., Iraqui, J. \& Share, D. L. (1993). Effects of listening to story reading on aspects of literacy acquisition in a diglossic situation. Reading Research Quarterly, 28, 71-79.

Feitelson, D., Kita B. \& Goldstein, Z. (1986). Effects of reading series stories to first graders on their comprehension and use of language. Research in the Teaching of English, 20, 339-356.

Heath, S B. (1980). What no bedtime story means: Narrative skills at home and school. Language and Society, 11, 49-76.

Junqueira, S. (1995). O macaco medroso ( $7^{\text {a }}$ ed.). São Paulo: Ática.

Karweit, N. (1994). The Effect of story reading on the language development of disadvantaged prekindergarten and kindergarten students. Em D. K. Dickinson (Org.), Bridges to literacy: Children, families, and schools (pp. 43-65). Cambridge: Blackwell.

Mason, J. M., Kerr, B. M., Sinha, S. \& McCormick, C. E. (1990). Shared-book reading in an Early Start program for at-risk children. National Reading Conference Yearbook, 39, 189-198.
Nagy, W. E. \& Herman, P. A. (1988). Breadth and depth of vocabulary knowledge: Implications for acquisition and instruction. Em M. G. E. Mckeown \& M. E. Curtis (Orgs.), The nature of vocabulary acquisition (pp. 19-35). Hillsdale, New Jersey: Lawrence Erlbaum.

Olson, D. R. (1977). From utterance to text: the bias of language in speech and writing. Harvard Educational Review, 47, 257-281.

Pinheiro, A. \& Keys, K. (1987). A word frequency count in Brazilian Portuguese. Manuscrito não-publicado, University of Dundee, Dundee.

Raz, I. S. \& Bryant, P. (1990). Social background, phonological awareness and children's reading. British Journal of Developmental Psychology, 8, 209-225.

Rego, L. L. B. (1988). A literatura infantil: Uma nova perspectiva da alfabetização na préescola. São Paulo: FTD.

Robbins, C. \& Ehri, L. C. (1994). Reading storybooks to kindergartners helps them learn new vocabulary words. Journal of Educational Psychology, 86, 5464.

Rosenhouse, J., Feitelson, D., Kita, B. \& Goldstein, Z. (1997). Interactive reading aloud to Israel first graders: Its contribution to literacy development. Reading Research Quarterly, 32, 168-183.

Siegel, S. (1956). Nomparametric statistics for the behavioral sciences. New York: McgrawHill.

Silva, M. A. S. (1988). Construindo a leitura e a escrita: Reflexões sobre uma prática alternativa em alfabetização. São Paulo: Ática.

Teale, W. H. (1989). Home background and young children's literacy development. Em W. H. E. Teale \& E. Sulzby (Orgs.), Emergent literacy: Writing and reading (pp. 173-206, $4^{\text {th }}$ ed.). Norwood, N J: Ablex.

Terzi, S. B. (1995). A Construção da Leitura: Uma experiência com crianças de meios iletrados. Campinas: Pontes, Editora da Unicamp.

Valdez-Menchaca, M. C. \& Whitehurst, G. J. (1992). Accelerating language development through picture book reading: A systematic extension to Mexican day care. Developmental Psychology, 28, 1106-1114.

Vale, M. (1992). O macaco vermelho ( $3^{\mathrm{a}}$ ed.). Belo Horizonte: Dimensão.

Wechsler, D. (2002). WIS C-III: Escala de Inteligência Wechslerpara Crianças: ManualAdaptação e Padronização Brasileira ( $3^{a}$ ed.). São Paulo: Casa do Psicólogo.

Weinberger, J. (1996). A longitudinal study of children's early literacy experiences at home and later literacy development at home and school. Journal of Research in Reading, 19, 14-25.

Wells, G. (1986). The meaning makers. Children learning language and using language to learn $\left(5^{n}\right.$ ed). New Hampshire: Heinemann Portsmouth.

Whitehurst, G. J., Arnold, D. S., Epstein, J. N., Angell, A. L., Smith, M \& Fischel, J. E. (1994a). A picture book reading intervention in day care and home for children from low-income families. Developmental Psychology, 30, 679-689.

Whitehurst, G. J., Epstein, J. N., Angel, A. L., Payne, A. C. \& cols. (1994b). Outcomes of an emergent literacy intervention in Head Start. Journal of Educational Psychology, 86, 542-555.

Whitehurst, G. J., Falco, F. L., Lonigan, C. L., Fischel, J. E., Debaryshe, B. D., Valdez-Menchaca, M. C. \& Caulfield, M. (1988). Accelerating language development through picture book reading. Developmental Psychology, 24, 552-559.

Recebido: 27/02/2003

Revisado: 02/07/2003

Aceite Final: 04/07/2003

Sobre as autoras

Maria José de Oliveira Fontes é Economista Doméstica e Mestre em Psicologia pelo Programa de Pós-graduação em Psicologia da Universidade Federal de Minas Gerais. É Professora da Universidade Federal de Viçosa.

Claudia Cardoso Martins é Mestre e Doutora pela University of Illinois e Pós-doutora pela University of Denver. É Professora da Universidade Federal de Minas Gerais. 


\section{ANEXO A}

\section{História: O sonho de Maria}

O maior Sonho de Maria era poder voar como os passarinhos.

Certo dia, ela encontrou no jardim uma pomba com a asa machucada.

Maria cuidou da pobre ave até ela ficar boa. A pombinha, que na verdade era uma fada, disse:

- Você mostrou que é uma boa menina e eu vou realizar o seu desejo.

E falou as palavras mágicas:

Camuru, camará, que ela comece a voar.

Maria ficou com o corpo bem leve e foi subindo devagar.

Voou bastante, apostou corrida com os passarinhos e achou engraçado ver como as pessoas lá embaixo ficaram parecendo formiguinhas. De repente, ela sentiu que estava descendo. $\mathrm{O}$ encantamento havia acabado.

\section{Teste de Compreensão}

Perguntas sobre a história - O sonho de Maria

1- Qual é o nome da história?

2- Quem aparece na história?

3- Qual era o sonho da Maria?

4- Quem realizou o sonho da Maria?

5- O que aconteceu depois?

6- O que aconteceu quando a Maria estava voando?

7- Como terminou a história?

\section{ANEXO B}

\section{História: O Sonho de Maria}

Exemplos de respostas

\section{PERGUNTA RESPOSTAS}

\section{ESCORE}

1- Qual é o nome da história?

2- Quem aparece na história

5- O que aconteceu depois?

6- O que aconteceu quando a
- Maria

- A menina que queria realizar o seu sonho

- O sonho da Maria

- Eu não sei não

- A pombinha, as

formiguinhas e a Maria

- Passarinho, a pomba e a

Maria

- A Maria cuidou bem, mas bem dela

- Ela foi e voou

- Ela ficou com o corpo

leve e saiu voando

- Ela voava com o passarinho

- Ela viu a gente lá de baixo parecendo formiguinha

- Ela queria apostá corrida com os passarinho e ela viu as criança igual formiguinha lá embaixo 1

0 


\section{ANEXO C}

\section{História: A flor e o passarinho}

Era uma vez uma flor que morava num quintal cheio de árvores grandes. A flor vivia muito triste pois não havia ninguém com quem pudesse conversar. As árvores grandes não gostavam dela e nunca a convidavam para brincar. Um dia, a flor viu um passarinho e resolveu conversar com ele. Ela foi logo dizendo que estava muito triste e sozinha.

- Por que você está tão triste? Perguntou o passarinho.

- Aqui fico muito sozinha, disse a flor. Não tenho amigos. Você poderia ajudar?

- Não se preocupe, respondeu o passarinho, tenho uma idéia para acabar com sua tristeza. E lá se foi ele voando rápido para um jardim vizinho.

Neste jardim o passarinho apanhou com o bico, várias sementes de flores. À noite, voltou para o quintal onde a florzinha morava e enquanto ela dormia, plantou as sementes na terra. Naquela noite, choveu muito. Ao amanhecer, a flor teve uma grande surpresa. O quintal parecia um lindo jardim!

Desde então, a flor viveu muito feliz, pois agora tinha muitas amigas para conversar.

\section{TESTE DE COMPREENSÃO}

\section{Perguntas sobre a história - A flor e o passarinho}

1- Qual o problema da flor?

2- $\quad$ O que ela mais queria?

3- Quem resolveu o problema da flor?

4- $\quad$ O que foi que o passarinho fez para ajudar a flor?

5- Qual foi a surpresa que a flor teve quando acordou?

6- Por que o quintal ficou parecendo um lindo jardim?

7- $\quad$ O que fez as sementes crescerem tão rápido?

8- $\quad$ Por que a flor ficou feliz no final da história?

9- $\quad$ O que você acha do passarinho da história? Por quê?

10- O que você acha das árvores nesta história? Por quê?

11- Qual o nome que você daria para essa história? Por que você acha que esse nome combina com a história que você ouviu? 